\title{
Drepanocitosis o anemia de células falciformes y embarazo
}

\author{
Camilo Libos Sayegh*; Luis Fernando Castaño Molano**
}

RESUMEN: La drepanocitosis es una patología frecuente en la costa pacífica colombiana. Se hace una revisión de esta patología en el embarazo, ilust rándola con un caso clínico y demostrando que la morbimortalidad materna y fetal disminuyen si se realiza un diagnóstico precoz y un manejo adecuado.

PALABRAS ClAVE: Drepanocitosis, Embarazo, Feto.

SUMMARY: The sickle cell anemia is a frecuent entity in the Pacific Colombian coast. It has been made a revision of this pathology in the pregnancy, demonstrating it with a clinical case and showing that if it's done a quick diagnosis and treatment, it diminishes the maternal and fetal morbimortality.

KEY WORDS: Sickle Cella Amemia, Pregnancy, Fetal

\section{Introducción}

Para una mejor comprensión de la patología es necesario analizar la formación de la hemoglobina, la cual comienza a partir de los eritroblastos y continúa a todo lo largo de la etapa normoblástica. Se ha visto que los eritrocitos recién salidos de la médula ósea a la circulación pueden producir pequeñas cantidades de hemoglobina por uno o dos días.

La molécula tiene dos componentes principales, el Hem y la Globina. La porción Hem deriva básicamente del ácido acético y la glicina, formados en las mitocondrias. El ácido acético pasa a ácido alfacetoglutárico en el ciclo de Krebs, y dos moléculas de este ácido se combinan con una molécula de glicina para formar un compuesto pirrólico. A su vez cuatro compuestos pirrólicos se unen para formar un compuesto de protoporfirina. Una de las protoporfirinas, la III, se combina con el hierro para formar el Hem. Finalmente cuatro moléculas de Hem se combinan con una molécula de Globina para formar la hemoglobina.

La molécula de Globina en el adulto sano está formado por dos cadenas Alfa y dos Beta. Sobre la cadena Beta va a ocurrir el cambio en la estructura de la hemoglobina que formará la drepanocitosis (1).

\section{Definición}

La drepanocitosis se caracteriza por la formación de Hemoglobina $S$ dada por el cambio de un aminoácido en la cadena Beta de la Hemoglobina, en el cual el ácido

\footnotetext{
* Residente III Gine cología y Obstetricia. Hospital Universitario de la Samaritana. Santa Fe de Bogotá, D.C.

** Instructor Departamento Ginecología y Obstetricia. Hospital Universitario de la Samaritana. Santafé de Bogotá, D.C.
}

glutámico es reemplazado por la valina en la posición seis $(1-4,12)$.

\section{Clasificación}

1 - Rasgo falciforme (Hemoglobina A-S).

2 - Anemia de Células Falciformes (Hemoglobina S-S).

3 - Doble estado Heterocigoto (Hemoglobina S-C, Hemoglobina S-D, Hemoglobina S-E, Hemoglobina SMemphis) $(13,15)$.

En pacientes con anemia y enfermedad drepanocítica, hay transmisión hereditaria en el $100 \%$ de los casos. En los demás hay probabilidades de que un $25 \%$ de las pacientes resulten homocigotos si el esposo es portador(5).

\section{Incidencia}

Se hizo una revisión de la literatura y se halló que el $0.2 \%$ de los pacientes presentan anemia $(4,12)$, mientras el $6 \%$ al $10 \%$ presentan rasgos drepanocíticos $(3,5,12)$. Esta incidencia es la encontrada en Estados Unidos, pues no hay un informe actualizado de estadísticas en Colombia.

Se da casi por seguro que el gen drepanocítico provino de una mutación aislada en el Africa central, y que su distribución actual obedece a factores como el comercio de esclavos hacia América, Arabia y la India (12).

Es importante anotar que en el sur occidente del país a lo largo de la costa del Pacífico, la patología se presenta con relativa frecuencia en la población negra (14).

\section{Fisiopatología}

La valina, que es el aminoácido diferente en la cadena de globina, causa una unión hidrofóbica entre los aminoácidos, formando así tetrámeros insolubles que se polimerizan y aglutinan en forma de cristales dentro del 
glóbulo rojo. Estos cambios alteran la forma normal de disco bicóncavo para darle el aspecto de media luna, el cual es característico para su diagnóstico.

Una vez alterada la morfología del eritrocito, se desencadena una agregación que obstruye la microcirculación, debido a un factor llamado trombospodina $(3,7,12)$. Esto puede conducir a uno de los siguientes eventos: Infarto del órgano comprometido, agregación plaquetaria por activación del factor de Von Willebrand, o desencadenar dolor, lo que comúnmente se ha denominado "Crisis drepanocítica".

La anemia se debe principalmente a la disminución de supervivencia eritrocítica asociada a eritropoyesis ineficaz. Los estudios in vitro con hematíes falciformes en condiciones de desoxigenación muestran una serie de cambios morfológicos que terminan con un drepanocito con largos filamentos. En condiciones de oxigenación el drepanocito adopta una forma normal. Si este efecto de conversión drepanocítica se repite varias veces, la célula acaba por perder su capacidad de regresar a la forma normal en condiciones de oxigenación y entonces el fenómeno drepanocítico es irreversible. La incapacidad de volver a adoptar la forma normal se debe probablemente a la pérdida progresiva de los microfilamentos y a la lesión de la membrana celular (12).

Existen ciertas condiciones que precipitan estos cambios como son: Trauma, infección, disbalance ácido base, deshidratación, anestesia, actividad física severa, frío y disminución de la presión arterial de oxígeno. (Por debajo de $60 \mathrm{~mm}$ de $\mathrm{Hg}$ en anemia y menor a $15 \mathrm{~mm} \mathrm{Hg}$ en rasgos) (2).

\section{Cuadro clínico}

El cuadro clínico es variable y va desde la paciente asintomática hasta aquella que presenta crisis graves.

Los trastornos más graves suelen diferenciarse de los rasgos drepanocíticos por el antecedente de crisis vasooclusivas dolorosas recurrentes caracterizados por dolor pulsátil, fiebre y leucocitosis con una duración de dos a seis días (12). Por lo general ocurren de uno a cuatro ataques al año, que se desencadenan por las condiciones precipitantes ya mencionadas, y pueden afectar cualquier órgano o sistema, sin excepción. No obstante, existen algunos más vulnerables que otros, como la microcirculación de las articulaciones, el sistema nervioso central y el sistema respiratorio. Entre las patologías a este nivel se encuentra el síndrome torácico, caracterizado por fiebre, dolor pleurítico, tos e infiltrados en los RX.

Otros órganos afectados son los intraabdominales, que pueden semejar un abdomen agudo. Entre los cuadros clínicos hallados tenemos la colelitiasis, que se presenta más frecuentemente en procesos crónicos de hemólisis y en un momento dado pueden dar cuadros de colecistitis aguda; La necrosis papilar renal, entre tanto, puede semejar un cuadro de infección urinaria. También se presenta también la apendicitis aguda $(3,6,12)$.

Por crisis de anemia súbita y reticulocitopenia puede afectarse el sistema hematopoyético. El tipo de crisis mas frecuente es la aplásica, la cual es autolimitada y asociada a infección (12). También están las crisis hemolíticas, asociadas a esferocitosis hereditaria; las crisis megaloblásticas asociadas a deplesión de folatos, y las crisis de secuestro esplénico, que producen esplenomegalia y en ciertos casos infarto esplénico (2-3).

Durante el embarazo las crisis son vasooclusivas, ocurren especialmente en la segunda mitad de la gestación y se caracterizan por producir ataques de dolor sobre todo en articulaciones, tórax y abdomen $(2,4)$.

\section{Impacto sobre la madre y el feto}

La drepanocitosis afecta a la madre en los siguientes tres aspectos:

1. Disminución de la Fertilidad, debida a disminución de los valores de FSH, LH y cortisol, independientemente de que los valores de las hormonas tiroideas T3 y T4 hayan sido afectadas o no (9).

2. Aumento de la incidencia de los trastornos hipertensivos durante el embarazo, al doble de su frecuencia (3).

3. Incremento en abortos y obitos, debido a la trombosis del lecho placentario.

La afección del feto está dada por un aumento en la incidencia de partos pretérminos, de bajo peso al nacer y de retardo en el crecimiento intrauterino (3-5).

\section{Morbimortalidad}

La morbilidad ha disminuido en la última década del $65 \%$ al $25 \%$.

La mortalidad materna se redujo en los últimos 20 años del $25 \%$ al $2 \%$.

Las causas más frecuentes de mortalidad son: Insuficiencia cardíaca congestiva, tromboembolismo pulmonar e insuficiencia renal aguda (5).

La mortalidad neonatal es de 85/1000 nacidos vivos.

\section{Diagnóstico}

En pacientes con anemia severa comúnmente se visualizan los drepanocitos, con su forma de media luna, en el frotis de sangre periférica. Aquellos pacientes que presentan rasgos de la enfermedad no tienen alteración en el frotis de sangre periférica. El diagnóstico definitivo se hace por electroforesis de hemoglobina $(2-3,12)$.

\section{Tratamiento}

El tratamiento de la drepanocitosis se plantea desde tres puntos de vista:

- Generalidades

- Tratamiento intraparto

- Tratamiento postparto

- Generalidades.- Para el tratamiento de la entidad debe iniciarse el suplemento de ácido fólico $(5 \mathrm{mgr})$, debido a que es necesario compensar el alto consumo de folatos causado por el proceso activo de replicación celular que se da en la médula ósea. Por lo general también se requiere suplemento de hierro $(3,5)$.

Es importante mantener a las pacientes bien hidratadas porque así disminuye la concentración intracorpuscular 
de hemoglobina, y con esto disminuyen las estructuras drepanocíticas.

Dentro de las crisis drepanocíticas es vital el manejo del dolor. Se deben buscar y tratar agresivamente las infecciones, sobre todo las urinarias, que muchas veces pasan desapercibidas, ya que éstas desencadenan las crisis por razones ya explicadas (2-4).

Existen dos tipos de transfusiones para el manejo de la drepanocitosis: Profilácticas y terapéuticas. Ambas buscan tanto disminuir la incidencia y severidad de las complicaciones como lograr el manejo del dolor $(5,10)$.

La transfusión profiláctica tiene dos formas de aplicación:

a) La primera transfusión en semana 28 y la segunda en semana 36. Si hay crisis es necesario hacer transfusiones adicionales.

b) Se dan glóbulos rojos empaquetados desde el inicio del embarazo.

El objetivo es mantener los valores de hemoglobina mayores de $8 \mathrm{gr} \%$ y hematocrito mayor a $25 \%$ con una concentración de hemoglobina S por debajo del 50\% (4-5).

Los inconvenientes de este tipo de transfusión son el desarrollo de hemosiderosis y haloanticuerpos, y el riesgo de transmision de enfermedades como hepatitis o sida $(3-5,8,12)$.

La transfusión terapéutica es la más recomendada para la anemia o el manejo de la crisis drepanocítica. Se utiliza para mejorar el pronóstico maternofetal (2-3).

- Tratamiento Intraparto.- Se debe realizar un monitoreo maternofetal intensivo para evitar las crisis intraparto y detectar cualquier tipo de sufrimiento fetal que se presente. Para esto hay que evitar la hipoxia y la acidosis. Es importante mantener a la paciente bien hidratada.

La cesárea se debe realizar únicamente por indicación obstétrica (3-4).

- Tratamiento Postparto.- Por los cambios hemodinámicos que ocurren en el puerperio inmediato, es necesaria una vigilancia hemodinámica materna para evitar las crisis que se puedan presentar $(2,4)$.

Los recién nacidos deben ser examinados para establecer la zigocidad con respecto a la hemoglobina $S$, y realizarles para su seguimiento electroforesis de celulosa acetato $(3,11)$.

\section{Caso Clínico}

Para ilustrar la revisión de la entidad que se comentó, se toma como ejemplo un caso clínico manejado en el Hospital Universitario del Valle en septiembre y octubre de 1993, durante la rotación por el servicio de perinatología realizada por el residente del hospital de La Samaritana de Bogotá.

\section{Historia No. 1074477}

Nombre: R. B. - Edad: 31 años

Natural y procedente de Santander de Quilichao (Cauca) Fecha de Ingreso de primera hospitalizacion: agosto 29/93 Fecha de Egreso de primera hospitalización: sept. 21/93 Fecha de Ingreso de segunda hospitalización: octubre 10/93 Fecha de Egreso de segunda hospitalización: octubre 21/93
M.C. Paciente remitida de Santander de Quilichao por artralgias que impiden la marcha más que todo en la articulación coxofemoral, con fiebre no cuantificada, hiporexia, coluria, ictericia y dolor pleurítico.

\section{Antecedentes Personales:}

Patológicos - Presentó cuadros similares en niñez, adolescencia y en los otros embarazos.

Transfusionales - Hace 2 años en el último embarazo por cuadro similar.

Ginecobstétricos - Menarquia 13 años; Ciclos 30/3; $\mathrm{g} 4 \mathrm{p} 4 \mathrm{a} 0 \mathrm{v} 2 \mathrm{~m} 2$

Embarazo gemelar de 28 semanas con mortinatos por crisis drepanocítica.

F.U.R. Febrero 1/93; Edad gestacional 29.5 semanas.

\section{Familiares:}

Hermana falleció hace 10 años por crisis drepanocítica.

\section{Examen Físico}

Paciente álgica, deshidratada y febril

TA 120/70; FC 120 ; To 39 C.; Peso 73 kg.

Ojos: Escleras ictéricas.

Tórax: Buena ventilación pulmonar, ruidos cardíacos taquicárdicos sin soplos.

Abdomen: AU $35 \mathrm{~cm}$. Primer feto presentación cefálica FCF 168/min Segundo feto presentación podálica FCF $176 / \mathrm{min}$.

No hay actividad uterina.

TV. Cuello largo posterior cerrado.

Extremidades: Dolor a la movilización de la cadera derecha.

Neurológico: No signos meníngeos. Examen normal.

ID: 1.Embarazo gemelar de 29.5 semanas por FUR.

2. ¿Síndrome febril a estudio: Colagenosis?; ¿Artritis cadera derecha?; ¿Drepanocitosis?

Se hospitaliza y se realiza Eco Obstétrica reportada como embarazo gemelar, monocoriónico, biamniótico de 29 semanas.

Laboratorios: Creatinina, ácido úrico, transaminasas, tiempos de coagulación, hemocultivos, urocultivo, serología, seroaglutinación, complemento, gota gruesa y antígeno australiano: Normales.

Parcial de orina: Bacterias ++, Leucocitos 12-15/ campo.

Cuadro Hemático: HB 9 gr - Hcto 27 - L 19.300 N 76\% - L 19\% - M 5\%

Anisositos +++

Poiquilositosis +++

Macrocitos ++

Policromasia ++

Cuerpos de Howell Jolly +

Drepanocitos Positivos.

Se inicia tratamiento con líquidos endovenosos a 120 cc. hora, ampicilina, acetaminofén y transfusión de 3 
unidades de glóbulos rojos empaquetados. Al tercer día se cambia antibiótico a cefacidal.

Valorada por ortopedia se descarta artritis.

Evoluciona hacia la mejoría con hidratación, suplemento de ácido fólico y hierro, y transfusiones en cuatro oportunidades. Se colocan corticoides para maduración pulmonar.

Se realizan perfiles biofísicos seriados los cuales son normales.

La paciente se da de alta el 21 de septiembre con un hematocrito de $37 \%$.

\section{Reingreso}

Remitida nuevamente del Hospital de Santander de Quilichao por presentar cifras tensionales altas sin signos premonitorios, sin edema ni proteinuria.

\section{Examen Físico}

TA $140 / 95 ; \mathrm{FC} 92 / \mathrm{min} ; \mathrm{T}^{\circ} 37^{\circ} \mathrm{C}$.

AU $39 \mathrm{cms}$; Primer feto en presentación cefálica FCF $140 / \mathrm{min}$.

Segundo feto en presentación podálica FCF 146/min.

TV. Cuello largo posterior cerrado.

I.D. 1. Embarazo gemelar de 36 semanas por FUR.

2. Hipertensión gestacional.
3. Drepanocitosis.

Exámenes de laboratorios realizados normales.

El 13 de octubre se realiza amniocentesis que reportó un índice $\mathrm{L} / \mathrm{E}$ de 1 por lo cual se colocaron nuevamente corticoides.

El 17 de octubre se practica NST la cual es no reactiva, perfil biofísico fetal de $4 / 10$, motivo por el cual se desembaraza por cesárea. Se obtuvo un primer producto de sexo masculino de 2800 grs, con apgar de $3 / 10$ al minuto, 6/10 a los 5 y 10 minutos con dificultad respiratoria que amerita traslado a cuidado intensivo neonatal. El segundo de sexo femenino de 2.400 grs con apgar de $6 / 10$ al min, $8 / 10$ a los 5 min y $10 / 10$ a los 10 minutos por lo cual se le pasa a la madre.

La paciente presenta crisis en el postoperatorio, caracterizado por artralgias y fiebre que requiere transfusión, con mejoría de la sintomatología.

Se da de alta el 21 de octubre de 1993 en buenas condiciones.

\section{Agradecimiento}

Al doctor Rodrigo Cifuentes Borrero, profesor titular de Ginecología y Obstetricia del Hospital Universitario del Valle, por permitir la publicación del caso que se utilizó para ilustrar el siguiente trabajo.

\section{BIBLIOGRAFIA}

1. Guyton AC. Eritrocitos, anemia y policitemia. Tratado de fisiología médica. Editado por Interamericana, Madrid, 1984.

2. Martin JN., Files J., Morrison JC. Sickle-cell crisis, In critical care Obstetrics, Edited by Blackwell Scientific Publications, Boston 1991.

3. Anderson HM. Maternal Hematology Disorders. In maternal Fetal Medicine: Principles and practice, edited by R.K. Creasy, and R. Resnick. W.B. Squnders, Philadelphia, 1989.

4. Morrison JC., Pryor JA. Hematologic Disorders. In Assessment and care of the fetus, Physiological, clinical and Medicolegal Principles, edited by Appleton \& Lange, Conecticut, 1990.

5. Arias F. Practical guide to High-Risk Pregnancy and Delivery, edited by Mosby-Year Book, Missouri, 1993.

6. Pollack CV Jr. Emergencies in sickle cell disease. Emerg. Med. Clin. North. Am. 1993; 11(2): 365-378.

7. Brittain HA., Eckman JR., Swerlick RA et al. Thrombospondin from activated platelets promotes sickle eritrocyte adherence to human microvascular endothelium under phisiologic flow: a potential role for platelet activation in sickle cell vaso-oclusion. Blood. 1993; 81(8): 2137-2143.
8. Dabrow MB., Wilkins JC. Hematologic Emergencies. Management of transfusion reactions and crises in sickle cell disease. Postgrad. Med. 1993; 93(5): 183-190.

9. El-Hasmi MA., Bahakim HM., Al-Fawaz I. Endocrine Funtions in sickle cell anaemia patiens. J. Trop. Pediatr. $1991 ; 38(6): 307-313$.

10. Cunningham FG., Pritchard JA., Mason R. Pregnancy and sickle cell Hemoglobinopathy: Results with and without prophilactic transfusions, Obstet, Gynecol. 1983; 62: 419.

11. Nussbaum RL., Powell C., Graham HL et al. Newborn screening for sickling hemoglobinopathies. Am. J. Dis. Child. 1984; 138: 44.

12. Mially JB. Anemias debidas a disminución de la supervivencia eritrocítica, hemoglobinopatías. Laboratorio en Hematología. 1989.

13. Wintrobe's. Síndromes Falciformes. Clinical Hematology. 1993.

14. Restrepo A. Anemias Hemolíticas. Hematología Clínica. Editado por Editorial Bedout, 1968.

15. Morrison JC. Hemoglobinopatías y embarazo. Clínicas Obstétricas y Ginecológicas. 1979; 22(4): 852-853. 